\section{Air transport and the fate of pneumothorax in pleural adhesions}

\author{
M M Haid, P Paladini, M Maccherini, \\ M Di Bisceglie, G Biagi, G Gotti
}

\begin{abstract}
Air travel is contraindicated in patients with a pneumothorax but was necessary because of the exigencies of war in three patients. Three patients with high velocity missile injuries to the chest and pleural adhesions are reported. All had to be evacuated by air, without an intercostal drain or oxygen supplement, from the war stricken area of Northern Somalia (Horn of Africa) to Mogadishu. Two patients with a partial pneumothorax flew on military transport aeroplanes at an altitude of $3000 \mathrm{~m}$ in a nonpressurised cabin and recovered rapidly after a few days in hospital. One patient, transported on a small Cessna aeroplane, died after developing bilateral tension pneumothoraces.
\end{abstract}

\section{(Thorax 1992;47:833-834)}

Pneumothorax is considered an absolute contraindication for air travel, as reduction of barometric pressure causes trapped gases to expand. ${ }^{1}$ During the conflict in Somalia medical personnel under extremely stressful circumstances had to evacuate three patients with penetrating chest wounds by air without facilities for providing a means of egress for the trapped pneumothorax. Two of the three patients survived.

\section{Case reports}

\section{PATIENT 1}

A 21 year old man suffered a penetrating wound to the left thorax and was admitted to hospital in Mogadishu after a two and a half hour air journey on a military transport aeroplane. $\mathrm{He}$ had a history of chronic dry cough. He had clinical signs that suggested a left sided pneumothorax and this was confirmed by chest radiography, which showed a partial (about $50 \%$ ) pneumothorax localised to the lower left pleural cavity (fig 1). No treatment was necessary other than needle thoracocentesis.

PATIENT 2

A 23 year old man was admitted to hospital in Mogadishu with a penetrating wound to the right thorax after a two and a half hour air journey on a military transport aeroplane.
There was no past history of any important chest disease apart from an influenza like illness accompanied by wheezing and dry cough.

On examination he was calm and cooperative. The respiration rate was $20 / \mathrm{min}$, pulse $96 / \mathrm{min}$ and regular, and blood pressure $110 / 80 \mathrm{~mm} \mathrm{Hg}$. The physical signs suggested a right sided haemopneumothorax. A chest radiograph showed a partial (roughly 20\%) right hydropneumothorax and upper zone shadowing (fig 2). A needle thoracocentesis was performed. He was discharged on the second day after admission and has remained well.

\section{PATIENT 3}

A 35 year old man with a penetrating injury to the left thorax was admitted to a police casualty hospital. He had been shot by an AK 47 rifle and was transported 24 hours after injury from Erigavo (Northern Somalia) to Mogadishu on a small Cessna aeroplane flying at an altitude of $2150 \mathrm{~m}$. The patient travelled in a cabin exposed to external barometric pressure and arrived at the hospital three hours later, having become restless and severely dyspnoeic. Little

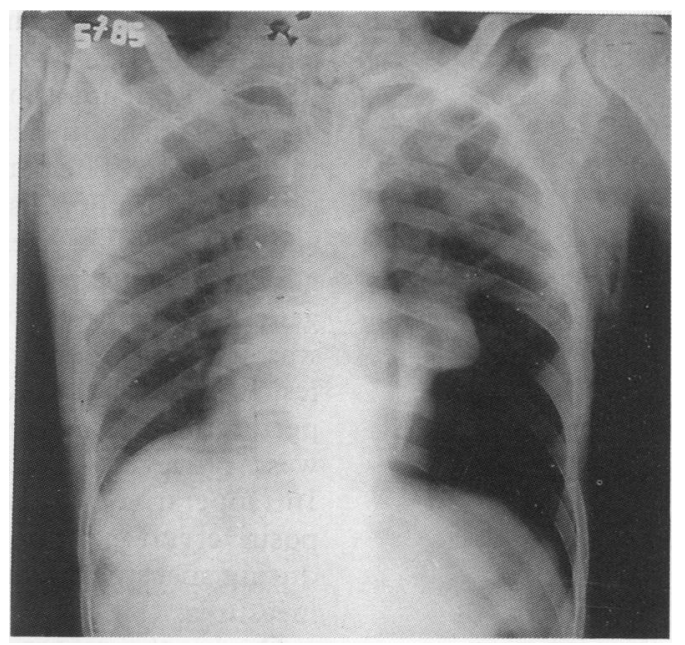

Figure 1 Patient 1: Radiograph showing a partial pneumothorax on the left side.

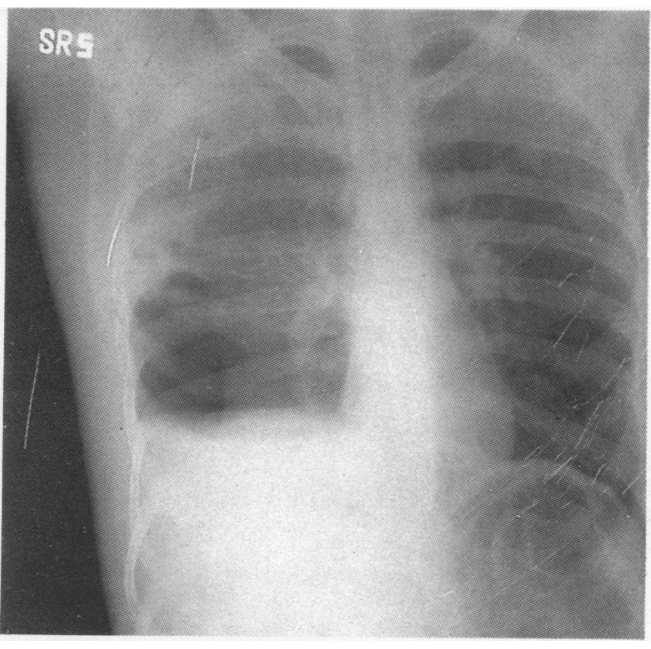

Figure 2 Patient 2: Radiograph showing a partial haemopneumothorax and parietal haematoma on the right side. 
Figure 3 Patient 3: Radiograph showing bilateral pneumothorax extensive subcutaneous emphysema, a large left lung contusion, and a

bullet.

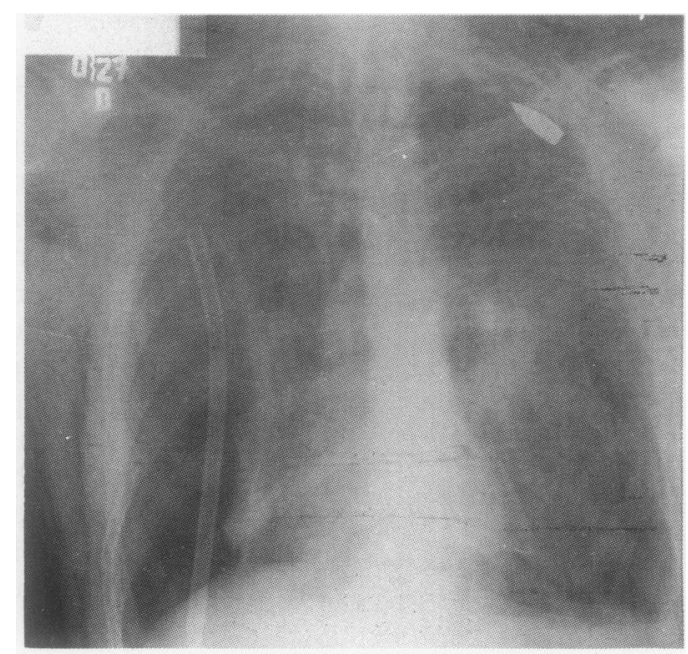

is known about the weather conditions during the flight.

The patient had a history of pulmonary tuberculosis and smoking. On examination he was confused and dyspnoeic with a rapid respiratory rate, a blood pressure of $110 / 60$ $\mathrm{mm} \mathrm{Hg}$, and a pulse rate of $104 / \mathrm{min}$. Extensive subcutaneous emphysema was present. He was severely hypoxaemic. A chest radiograph shortly after admission showed a right sided pneumothorax and extensive left sided shadowing; a right side chest tube was inserted. A chest radiograph two hours later showed a new left sided pneumothorax (fig 3). A chest tube was inserted on the left side but the lung failed to re-expand. The patient's progressively worsening respiratory distress, continued air leak, and considerable haemoptysis prompted surgery. A left posterolateral thoracotomy under general anaesthesia was performed. The lung was freed from the chest wall and no major lesion was found except for two pulmonary perforations, which were oversewn. The bullet was retrieved from the dorsal muscles. Intraoperative ventilation was controlled with positive end expiratory pressure. Monitoring during anaesthesia was limited to non-invasive measures.

During the postoperative period the patient continued to be restless and severely dyspnoeic. The lungs did not re-expand fully despite resuscitative measures and oxygen enriched ventilation (with an ambubag via a tracheostomy). He died of hypoxaemia on the fourth day after injury. Owing to the war conditions a necropsy was not possible.

\section{Discussion}

The risk of air transport for patients with a pneumothorax is well known. ${ }^{1}$ The first two patients fared well, as they had peripheral lung lesions with minimal lung contusion and the resulting air leak presumably sealed. The third patient had a central lesion, resulting in a massive leak of air, which we assume passed into the anterior mediastinum as the mediastinal aspect of the lung is usually less adherent. Further accumulation of air from the lung laceration and from mediastinal extension of subcutaneous emphysema may have caused the air to spread into the right pleural space. Pulmonary laceration compounded possibly by pleural adhesions from old tuberculosis could have resulted in massive mediastinal and subcutaneous emphysema without the development of a pneumothorax on the left. ${ }^{2}$ This may explain why the left pneumothorax appeared only after the right pneumothorax had been drained. ${ }^{2}$ His exposure to high altitude during air travel seems likely to have been responsible for the expansion and dissipation of the trapped air in the mediastinum.

The patient died of hypoxaemia despite vigorous ventilation via a tracheostomy with $100 \%$ oxygen. Although the pneumothoraces and chronic pulmonary disease may have contributed to this picture, shunting of blood through the contused lung with no gas exchange was probably the main factor. ${ }^{34}$

Although two patients with a partial pneumothorax survived air travel, chest drainage before evacuation is undoubtedly the safest option and should be carried out whenever possible.

1 Stonehill RB. Air travel and the cardiopulmonary patient. Postgraduate Med 1962;32:387-93.

2 Besson A, Saegesser F. A colour atlas of chest trauma and associated injuries. London: Wolfe, 1982:134-9, 309-42.

3 Wanebo H, Van Dyke J. The high velocity pulmonary injury: relation to traumatic wet lung injury. $J$ Thorac Cardiovasc Surg 1972;64:537-50.

4 Fischer RP, Geiger JP, Guernsey JM. Pulmonary resection for severe pulmonary contusions secondary to high velocity missile wounds. J Trauma 1974;14:293-302. 